This is a valuable statement of current practice in this country for rehabilitation of the lower limb amputee. While this service, which has developed from the care provided for the amputees of the two world wars, has many admirable points there is still room for improvement. This might be achieved by a closer integration of the amputee rehabilitation and prosthetic services into orthopaedic units with an adequate provision of beds during limb fitting and walking training. For this to be successful the average orthopaedic surgeon would have to know very much more about the problems which are so admirably described in Mr Humm's book.-Douglas W. LAMB.

Scoliosis. Edited by P. A. Zorab, M.D., M.R.C.P., Physician to Brompton Hospital, Sir Halley Stewart Research Fellow, Institute of Diseases of the Chest; with six other contributors. Foreword by Professor Sir Herbert Seddon, C.M.G. $22 \cdot 5 \mathrm{~cm} . \times 14.5 \mathrm{~cm}$. Pp. xii +87 , with many figures (plus a frontispiece) and some tables. Index. 1969. London: William Heinemann Medical Books Limited. Price 25s.

This is a short and valuable monograph by Dr Philip Zorab and his colleagues at the Institute of Diseases of the Chest. It covers what is known of the effects of scoliosis upon the structure of the heart and lungs and their function.

Zorab has been the prime mover in this country in investigating the deleterious effects that thoracic scoliosis has upon the respiratory and cardiac functions. Orthopaedic surgeons are too often unaware of the dire results of scoliosis in the thorax. A patient who has had a thoracic scoliosis of more than 75 degrees is liable to develop cor pulmonale in middle or late middle life; death is then common within two years of its onset; it is a particularly distressing illness. Those who have witnessed the rapid deterioration of a patient previously active will never forget the potential of scoliosis to kill.

This monograph contains all that the orthopaedic surgeon needs to know of the problems to be faced and will again underline the need to control scoliosis and prevent deformity severe enough to cause serious and sometimes fatal effects upon the heart and lungs. Dr Zorab and his colleagues are to be congratulated on producing such a brief but excellent monograph. Charles Manning of the Institute of Orthopaedics gives the surgical introduction to the book.-J. I. P. JAMES.

The Spine-A Radiological Text and Atlas. By Bernard S. EpsteIn, M.D.; Clinical Professor of Radiology, the Albert Einstein College of Medicine, New York; Director, Department of Radiology, the Long Island Jewish Hospital, New Hyde Park, New York; Radiologist-in-Chief, the Long Island Jewish Hospital-Queens Hospital Center Affiliation, New York. Third edition. $26 \mathrm{~cm} . \times 19 \mathrm{~cm}$. Pp. xiv +730 , with 1251 illustrations in 482 figures. Index. 1969. Philadephia: Lea \& Febiger. London: Henry Kimpton. Price $f 1515 \mathrm{~s}$.

This is a third edition of a well-respected standard textbook of radiology. The author is an expert on myelography and in this edition has brought the subject up to date with full details of removal of radiopaque medium after screening by siphonage and the use of image intensifier, cine-radiography, filming and video-tape. He comments on the use of air-myelography particularly as an aid to percutaneous cordotomy, and on water soluble contrast media, mentioning the complications. He regards the necessity for spinal anaesthesia as a very serious drawback limiting the examination of the upper part of the spinal canal. Dr Epstein states that "no myelographic examination is considered complete unless the patient is investigated from the caudal sack to the upper cervical area, and when indicated the posterior fossa." With this I think most orthopaedic surgeons would agree.

In general this textbook is designed for radiologists and is a standard work. The system of short summaries of the literature on each condition with guidance from the author's experience is open to criticism in that the conclusions may be dogmatic on subjects which are somewhat controversial, or literature may be mentioned with no conclusion by the author. However, the references at the end of each chapter enable the reader to refer directly to the relevant literature.

I noticed only one radiograph reproduced upside down. The standard of printing, reproduction and layout is excellent.-Charles MANNING.

Research in Muscular Dystrophy. The Proceedings of the Fourth Symposium on Current Research in Muscular Dystrophy held at the National Hospital, Queen Square, London, W.C.1, January 11-12.

1968. Edited by the Members of the Research Committee of the Muscular Dystrophy Group-

Chairman, J. N. Cumings. $23 \mathrm{~cm} . \times 15 \mathrm{~cm}$. Pp. xi +472 , with many figures and tables. 1968.

London: Pitman Medical Publishing Co. Ltd. Price 60s.

The contributions are all by workers supported wholly or partially by the Muscular Dystrophy Group of Great Britain which has now been in existence for ten years. The activities of the Group

VOL. $51 \mathrm{~B}$, NO. 4, NOVEMBER 1969 
are discussed by Professor Nattrass in the Joan Vincent Memorial Lecture, which opens the symposium. The Group has recently broadened its field of interest and has decided to support research concerned with all types of disease affecting muscle and not to confine its attention to muscular dystrophy as such.

This alteration in policy is reflected in the contributions to the fourth symposium. These have been divided into four sections, devoted respectively to clinical and genetic studies, anatomical and pathological investigations, biochemistry and finally neurophysiology. A very wide range of topics is covered and the various papers indicate the intense activity in this field at present. All those concerned with disorders of the locomotor system will find much of interest in this book-P. K. THOMAS.

The Hand. Journal of the British Society for Surgery of the Hand. Volume 1, Number 1, March 1969. Editors: H. Graham Stack, F.R.C.S., and Harold Bolton, Ch.M., F.R.C.S. Published twice yearly, in March and September. Subscription rate $£ 2$ (\$5) per annum, payable to the British Society for Surgery of the Hand, c/o Westhay, Mount Avenue, Hutton, Essex.

The marriage of the "Hand Surgeons Club of Great Britain" and the "Second Hand Club" has brought forth the expected paper progeny, though the names of the parents have now been changed to the British Society for Surgery of the Hand. Although produced in simple format the quality of the printing is excellent; illustrations are limited to clear line drawings. The need for a wider medium to spread the growing volume of knowledge of hand surgery has long been felt. This little book is probably only the beginning; it is a good one and will grow.-J. G. BonNIN.

Injury. The British Journal of Accident Surgery. Volume 1, Number 1, July 1969. Editorial Committee: P. S. London (Chairman), R. L. Batten (Editor) and M. F. Porter (Deputy Editor). Published quarterly. Bristol: John Wright \& Sons Limited. Annual subscription $£ 44$ s. Single copies $25 s$.

Readers of this Journal with particular interest in trauma will be glad to know of the appearance of the first volume of "Injury" to be published quarterly. Its inspiration comes chiefly from the Birmingham Accident Hospital, but it has also attracted authors from abroad and undoubtedly as it develops will attract contributors from a wide field.-J. G. BonNiN.

\section{BOOKS OF ORTHOPAEDIC INTEREST}

Essai de Classification des Dysplasies Spondylo-Epiphysaires. (Essay in the Classification of Spondylo-Epiphysial Dysplasias.) By P. Maroteaux, R. Wiedemann, J. Spranger, K. Kozlowski and L. Lenzi. Pp. 93, with 59 figures. 1968. Lyon: Simep éditions. Price 25 Francs.

The difficulty in classifying the irregular skeletal growth disturbances is that they are so rare that with the exception of Morquio's disease it has proved difficult to group the other variants under specific names. A praiseworthy attempt to improve the situation has been made by a group of orthopaedic surgeons from Paris, Kiel, Cracow and Pavia. They too suffer from a shortage of material, but their attempt to classify the sub-groups is of interest and may stimulate others.

Traumatismele Osteoarticulare. (Bone and Joint Injury.) Edited by Al. D. Radulescu. Volume II. Pp. 495, with 228 figures. 1968. Bucarest: Revue Roumaine de Medecine Interne. Price Lei 40.

The first volume of this textbook was mentioned in the Journal of Bone and Joint Surgery, 1968, 50-B, 688.

Fractures and Orthopaedic Surgery for Nurses and Physiotherapists. By Arthur NAYLOR, Ch.M., M.B., M.Sc. (Sheff.), F.R.C.S.(Eng.), F.R.C.S.(Edin.). Foreword by Sir Frank HoldsworTH, M.A., M.Chir., F.R.C.S. Sixth edition. Pp. xvi +394 , with 300 figures, some in colour. Index. 1968. Edinburgh and London: E. \& S. Livingstone Ltd. Price 40s.

This book covers in a relatively small compass most of the field of orthopaedics and associated trauma that a nurse or physiotherapist is likely to meet or have to treat. Much of the text has been brought up to date in this new edition but many of the illustrations are not up to the same standard and some of them could be omitted without disadvantage.

The Clinical Appearance of Low Back Disorders in the City of Gothenburg, Sweden. Comparisons of Incapacitated Probands with Matched Controls. By Jiri Horal. Pp. 109, with 7 figures and many tables. 1969. Copenhagen: Munksgaard. (Acta Orthopaedica Scandinavica, Supplementum No. 118.) Price Dan.kr.40.00.

A group of cases sick-listed for spinal disorder in Gothenburg were selected and compared with a similar age and sex group. No striking observations have come out of this, but the paper will be of interest chiefly to industrial medical officers and those working in the field of occupational health. 